\title{
SORGOLEONE: BENZOQUINONA LIPÍDICA DE SORGO COM EFEITOS ALELOPÁTICOS NA AGRICULTURA COMO HERBICIDA
}

\author{
I.L.V.L. Santos, C.R.C. da Silva, S.L. dos Santos, M.M.D. Maia
}

Universidade Federal Rural de Pernambuco, Departamento de Biologia, Laboratório deGenética, Bioquímica e Sequenciamento de DNA, Rua Dom Manoel de Medeiros, s/no, CEP 52171-900, Recife, PE, Brasil. E-mail: igorsantosbiologo@gmail.com

\section{RESUMO}

A cultura do sorgo cresceu rapidamente nestes últimos anos, por ser uma planta com características xerófilas, apresentando um aumento de sua produção principalmente na região nordeste devido a sua capacidade de suportar ambientes de cultivo mais secos. As ervas daninhas são um grande problema para os cultivares, pois estas podem reduzir significativamente a produção de grãos, particularmente quando surgem nas fases iniciais das culturas. Visando a obtenção de culturas resistentes às ervas daninhas, estudos têm sido realizados demonstrando que algumas plantas possuem uma defesa natural que consiste na capacidade de um organismo produzir metabólitos que atuam inibindo ou o crescimento ou o desenvolvimento de outros organismos que estão próximos; a esta capacidade dá-se o nome de alelopatia. O sorgo é uma das plantas que possuem sua alelopatia comprovada, produzindo um complexo de substâncias lipídicas e proteínas denominados genericamente de sorgoleone, tendo como seu principal composto o 2-hidroxi-5-metoxi-3-[(Z,Z)-8',11',14'-pentadecatrieno]-p-benzoquinona, que é naturalmente liberado para o solo a partir dos tricomas das suas raízes e, no momento em que entram em contato com as ervas daninhas, inibem seu crescimento. Devido a tais características inerentes à cultura do sorgo, este trabalho tem como objetivo discorrer sobre os possíveis benefícios do uso desse cereal devido a sua comprovada alelopatia, bem como informar os conhecidos mecanismos de produção e atuação dos principais compostos constituintes do sorgoleone produzidos pelas suas raízes.

PALAVRAS-CHAVE: Aleloquímicos, quinonas, ervas daninhas, controle biológico, Sorghumbicolor.

\section{ABSTRACT}

SORGOLEONE: LIPIDIC BENZOQUINONE OF SORGHUM WITH ALLELOPATHIC EFFECTS IN AGRICULTURE AS A HERBICIDE. The sorghum crop has grown rapidly in recent years, for being a plant with xerophilous characteristics; its production has especially increased in Northeastern Brazil due to its ability to withstand dry environments. Weeds are a major problem for grain crops, as these can significantly reduce yield, particularly when they emerge in the early stages of crops. To obtain crops resistant to weeds, studies have been conducted to demonstrate that some plants have a natural defense consisting in an organism's ability to produce metabolites that act to either inhibit or stimulate growth and development of other organisms grown in the same environment, which is called allelopathy. Sorghum is one of the plants that possess proven allelopathy, producing a set of lipid complex substances and proteins generically called sorgoleone, having as its main compound 2-hydroxy-5-methoxy-3-[(Z,Z)-8',11',14'-pentadecatriene]-p-benzoquinone, which is naturally released into the soil from their roots and trichomes, inhibiting the growth of weeds upon contact with them. Because of these inherent characteristics of the sorghum crop, the present work aims to discuss the possible benefits of using this cereal, due to its allelopathic effects, as well as to inform about the known mechanisms of production and action of the main constituent compounds of sorgoleone and other compounds produced by the plant's roots.

KEY WORDS: Allelochemicals, quinone, weeds, biological control, Sorghum bicolor.

\section{INTRODUÇÃO}

O sorgo é um importante cereal cultivado em todo o mundo devido particularmente a sua alta produtividade e composição nutricional que é semelhante a do milho. Ademais, ele pode ser utilizado no controle de ervas daninhas que têm sido um grande problema para diversas culturas reduzindo significativamente suas produções, principalmente quando é empregado em sistemas 
de cultivo rotativo ou consorciado. Isto é possível devido à capacidade que ele tem de produzir substâncias nos tricomas de suas raízes. Essa mistura de substâncias lipídicas, associadas a enzimas especializadas, são conhecidas como sorgoleone e são capazes de se manterem presentes no solo por longos períodos de tempo.

$\mathrm{O}$ advento e aplicabilidade da biotecnologia na agricultura propiciaram a utilização de ferramentas da engenharia genética para o controle de diversas pragas, dentre elas as ervas daninhas. Isto propiciou a redução do uso de defensivos químicos favorecendo desse modo uma produção mais saudável das culturas. Dito isto, o controle das ervas daninhas na agricultura moderna pode residir no desenvolvimen-to de plantas geneticamente modificadas ou que possuam uma inibição natural a essas pragas.

Pesquisas têm sido realizadas prospectando genes e plantas que favoreçam essa inibição natural, consistindo na produção de substâncias alelopáticas que atuam inibindo o crescimento e o desenvolvimento de outros organismos que seencontram próximos. Entre os organismos alelopáticos quejá foramidentificados na natureza, têm-se as bactérias, liquens, fungos e as plantas. Esses últimos podem utilizar aleloquímicos nas suas relações planta-planta, planta-inseto e até mesmo planta-herbívoro.

Por sua reconhecida alelopatia, o sorgo tem sido utilizado em sistemas de cultivo consorciado na tentativa de diminuir o uso de herbicidas químicos. Isto só é possível devido à produção de compostos com atividade biológica denominado de sorgoleone. Este exsudado naturalmente em quantidades relevantes nos tricomas das raízes do sorgo, que quando em contato com as ervas daninhas inibem seu crescimento por atuarem, principalmente, na inibição da via fotossintética dessa praga.

Devido a tais características intrínsecas à cultura do sorgo, este trabalho tem como principal objetivo informar sobre os possíveis benefícios do uso desse cereal na agricultura devido a sua comprovada alelopatia, bem como esclarecer os mecanismos de produção e atuação das substâncias produzidas principalmente em seus tricomas.

\section{CULTURA DO SORGO}

\section{Origem histórica e tipos}

O sorgo (Sorghum bicolor L. Moench) é originário da África Central onde foi inicialmente reconhecido nas regiões da Etiópia e Sudão de onde foi disseminado para toda a África e Ásia, posteriormente aportou no continente americano e australiano transportado pelos principalmente pelos escravos
(TABOSA, 2002). Atualmente, o sorgo é um dos principais cereais cultivados em todo o mundo (Medraour et al., 2007; Wu et al., 2010). Destaca-se particularmente por sua produção em regiões de alta temperatura e baixa precipitação, locais onde a cultura atinge altas produções de forragem e grãos (TABOSA, 2002). Esses são os dois principais objetivos de produção desta cultura servindo tanto para o propósito de forragem destinando-se a obtenção de biomassa, quanto para a alimentação humana ou animal geralmente na forma de grãos (NIMBAL et al., 1996a). Entretanto, ainda existem outros dois tipos conhecidos como vassoura e sacarino, este último utilizado para produzir açúcar e também na produção de etanol (LAOPAiBOON et al., 2009). Com essas possibilidades de produto final diversificado, verifica-se a vasta aplicabilidade prática dessa cultura demonstrando sua grande importância para a economia mundial. O sorgo cultivado hoje no mundo está subdividido em cinco raças principais, guinea, kafir, durra, bicolor, e caudatum (Medraou et al., 2007).

\section{Produção de sorgo no Brasil}

O desenvolvimento da cultura do sorgo no Brasil ocorre prioritariamente nas regiões Sudeste, Sul e Centro-Oeste. Devido a sua característica intrínseca de maior tolerância ao déficit hídrico, tem potencialidade para o cultivo na região Nordeste, onde atualmente é cultivado principalmente por pequenos produtores em sistemas consorciados. Essa região apresentou o segundo maior percentual de crescimento de área plantada com 1.995,52\% de crescimento (SANTOS et al., 2010). Nesta região, o Estado da Bahia é o maior produtor com cerca de 115,1 t/ha (toneladas por hectare) e o Rio Grande do Norte ocupa a segunda posição com $8,1 \mathrm{t} / \mathrm{ha}$, produção 2010/2011 (ConpanhiA..., 2011) (Tabela 1). Nesse contexto o sorgo vem demonstrando ser de grande importância para os agricultores locais destes estados (SANTOS et al., 2010).

Um dos fatores que mais contribuiu para este aumento nos últimos anos tem sido a dificuldade no controle de plantas daninhas em razão da sensibilidade de diversas culturas aos herbicidas graminicidas comercializados no Brasil. Devido a sua alelopatia comprovada, o sorgo tem se tornado um cultivar bastante importante em plantações com rotina de sistema consorciado fazendo com que, desse modo, aumente a sua área plantada (ARCHANGELO et al., 2002). Nestes casos, a agricultura se utiliza da alelopatia do sorgo diminuindo assim o uso de controles herbicidas sintéticos danosos ao meio ambiente favorecendo dessa maneira uma produção de grãos mais saudável ao consumo. 


\section{ALELOPATIA}

A alelopatia é a capacidade de um organismo produzir metabólitos que atuam inibindo ou estimulando crescimento ou o desenvolvimento de outros organismos, que estão próximos e que competem por recursos limitados como: nutrientes, água e luz (WeIr et al., 2004; Golisz et al., 2008).

O termo alelopatia provém do latin allelon (um ao outro) e pathos (sofrer) referindo-se a inibição química de uma espécie por outra. Em torno de 300 antes de Cristo o botânico grego Theophrastus foi, possivelmente, a primeira pessoa a reconhecer as propriedades alelopáticas das plantas relacionando-as com a exaustão do solo para certas culturas. Um dos principais problemas no estudo desse fenômeno é a dificuldade em desenvolver experimentos controlados e isentos de influências químicas externas. Com isso, pouco é realmente conhecido a respeito do mecanismo pelo qual as substâncias alelopáticas causam fitotoxicidade (WeIR et al., 2004).

Apesar de pouco conhecida, a alelopatia oferece a possibilidade de realizar um controle biorracional das ervas daninhas devido à produção e liberação pela própria cultura de substâncias aleloquímicas com atividade biológica (MACíAs et al., 2007; BLAIR et al., 2009). Defendida por muitos pesquisadores, essa opção possibilita o desenvolvimento de culturas transgênicas variadas que produzam sua própria defesa contra as ervas daninhas utilizando as ferramentas da engenharia genética (BAIS, et al., 2004; BAERSON et al., 2008a). Várias espécies de plantas são conhecidas por produzirem aleloquímicos em diferentes partes como folhas, flores, sementes, frutos e raízes. Esta produção pode ocorrer tanto em plantas vivas quanto, em alguns casos, mortas (YANG et al., 2004).

O controle de ervas daninhas com herbicidas, embora efetivo, é bastante oneroso, além de aumentar a problemática de conceitos públicos ligados à saúde ambiental (YANG et al., 2004; DAYAN et al., 2009a). O controle de ervas daninha na agricultura moderna pode residir no uso de plantas biotecnologicamente modificadas para resistir e até destruir tais agressores, especialmente aqueles ligados a espécieschave da agricultura como a soja, milho, feijão, arroz, sorgo e tantas outras (YANG et al., 2004). Além disso, aleloquímicos liberados por espécies de grãos como cevada, centeio e sorgo podem atuar significativamente como supressores de plantas daninhas quando utilizadas com o propósito de forragem ou em sistemas de consórcio (BAERSON et al., 2005; BAERsON et al., 2008b). Entre os organismos alelopáticos que já foram identificados na natureza, têm-se as bactérias, liquens, fungos e plantas (Wu et al., 1999; WeIR et al.; 2004). Talvez, em função da facilidade de observação dessas interações em plantas, várias já foram identificadas como sendo potencialmente alelopáticas e, atualmente, há um crescente interesse na identificação desses indivíduos, uma vez que o estudo de seus princípios ativos e sua atuação possibilita o incremento destas substâncias na agricultura, favorecendoa diminuiçãona utilização de herbicidas.

Plantas que apresentam potencial alelopático contra outros organismos podem promover novas mudanças no ecossistema que teriam impacto em longo prazo em outras comunidades. Metabólitos secundários que são depositados no solo pelos exsudados ou pela morte das plantas fornecem uma rica fonte de carbono que é utilizada por populações microbianas do solo (BELz, 2007). Esses metabólitos influenciam a composição microbiana da rizosfera afetando as plantas que interagem com ela (WeIR et al., 2004; FunNELL-HARRIS et al., 2008). Por outro lado, em alguns casos, micro-organismos da rizosfera podem favorecer a degradação de certos compostos alelopáticos diminuindo, assim, sua fitotoxicidade, particularmente nos casos de ácidos fenólicos. Estes micro-organismos do solo rapidamente mineralizam compostos fenólicos porque possuem maior relação de energia por peso quando comparados com açúcares simples (WEIr et al., 2004; GIMSING et al., 2009).

Tabela 1 - Sorgo no Brasil, série histórica da produção em toneladas por mil hectares de área plantada dos períodos de 1976/1977 (início dos índices de produção) e 2010/2011.

\begin{tabular}{lccc}
\hline Região & $1976 / 1977$ & $2010 / 2011^{*}$ & Aumento em \% \\
\hline Norte & - & 18,4 & - \\
Nordeste & 6,7 & 133,7 & $1,995,52$ \\
Centro-Oeste & 19,6 & 470,6 & 2401,02 \\
Sudeste & 59,0 & 153,0 & 259,32 \\
Sul & 92,3 & 19,3 & 20,91 \\
\hline Brasil & 177,6 & 776,6 & 447,63 \\
\hline
\end{tabular}

Fonte: CONAB (julho 2011)

*Dados Estimados: sujeitos a mudanças 
A alelopatia representa então uma forma de guerra química entre plantas vizinhas competindo por recursos limitados. Tem sido proposto que as interações alelopáticas podem ter efeitos profundos sobre a evolução das comunidades vegetais pela perda de espécies sensíveis através da interferência química causada por esse efeito impondo, assim, uma pressão seletiva que favorece os indivíduos resistentes à inibição de um dado aleloquímico (BAERSOn et al., 2008b).

\section{SORGOLEONE}

\section{Composto e análogos}

O termo sorgoleone é mais frequentemente utilizado para descrever o componente predominante dos exsudados das raízes de sorgo denominado de 2-hidroxi-5-metoxi-3-[(Z,Z)$8^{\prime}, 11^{\prime}, 14^{\prime}$-pentadecatrieno]-p-benzoquinona (DAYAN, 2006) (Fig. 1). Também é referido em bancos de dados como CHEBI:61098, CPD-10259, 4-methoxy-3,6-dioxo-2-[(8Z,11Z)-pentadeca-8,11,14-trien-1-yl]cyclohexa-1,4-dien-1-olate.

O sorgoleone e sua 1,4-hidroquinona compõem cerca de $90 \%$ da secreção oleosa das raízes de sorgo, os $10 \%$ restantes da composição do exsudado de sorgo são de substâncias menores, embora semelhantes ao sorgoleone diferindo em muitos casos no comprimento e no grau de saturação das cadeias alifáticas e na substituição do anel de quinona (CZARNOTA et al., 2001; DAYAN et al., 2009b).

Ademais, o termo sorgoleone também é usado para descrever um grupo de p-benzoquinonas lipofílicas estruturalmente relacionadas ao 2-hidroxi-5-metoxi-3-[(Z,Z)-8',11',14'-pentadecatrieno]-p-benzoquinona, que também são produzidos pelas raízes de sorgo tendo substituições hidroxi e metoxi nas posições 2 e 5 , respectivamente, ou, ainda, caudas alifáticas de 15 ou 17 carbonos e vários graus de insaturação na posição 3 (BARBOSA et al., 1998; DAYAN et al., 2003).

\section{Biossíntese e regulação}

Estudos recentes têm mostrado que a biossíntese do sorgoleone ocorre constitutivamente durante o estabelecimento inicial da plântula. Após a exsudação a hidroquinona menos estável rapidamente oxida para uma forma de benzoquinona altamente fitotóxica (MARCHI et al., 2008). Esta substância possui uma longa meia-vida persistindo no solo e afetando muitos alvos celulares por longos períodos de tempo fazendo dela uma excelente alternativa natural frente aos herbicidas sintéticos (DAYAN et al., 2007; BAERSON et al., 2008b; BARBOSA et al., 2010). Embora a localização celular e as etapas da via biossintética envolvidas na produção do sorgoleone tenham sido determinadas (DAYAN et al., 2003; PAN et al., 2007; BAERSON et al., 2008b), há poucos dados disponíveis sobre os fatores que afetam a sua biossíntese (UDDIN et al., 2010).
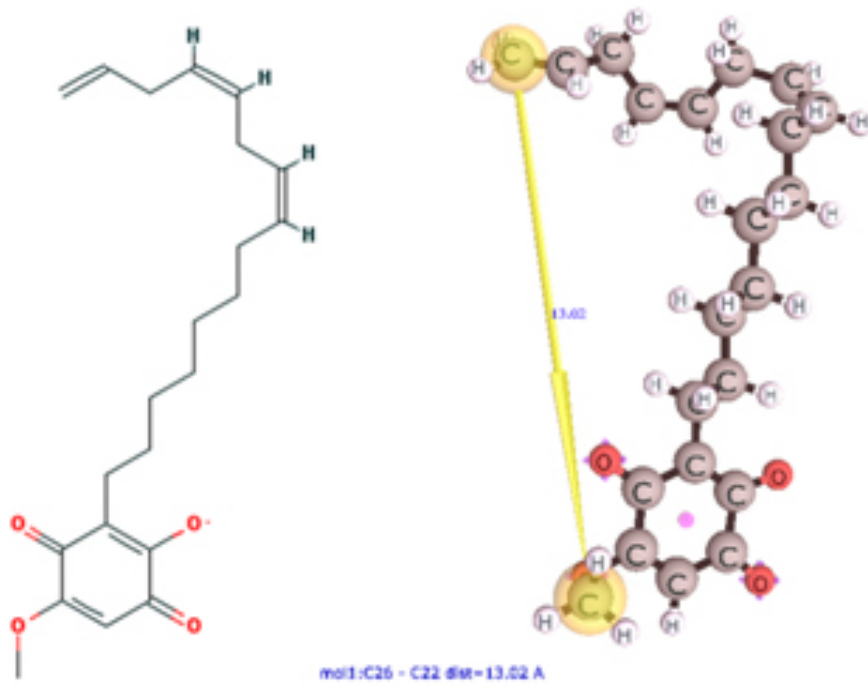

Compound ID: 25246122

Molecular Weight: $357.46326[\mathrm{~g} / \mathrm{mol}]$

Molecular Formula: $\mathrm{C}_{22} \mathrm{H}_{29} \mathrm{O}_{4}{ }^{-}$

XLogP3-AA: 6.7

H-Bond Donor: 0

H-Bond Accentor: 4

*Para informações adicionais consultar a fonte.

Fig. 1 - Representação da molécula de Sorgoleone, a seta amarela indica a distância de 13,02 Ångströms entre os carbonos indicados, em vermelho as moléculas de oxigênio.

*Fonte: http:/ / pubchem.ncbi.nlm.nih.gov/summary/summary.cgi?cid=25246122. 
Evidências microscópicas foram obtidas sugerindo que o sorgoleone é sintetizado em associação com o retículo endoplasmático (YANG et al., 2004). A biossíntese do sorgoleone provavelmente ocorre exclusivamente nos tricomas das raízes que aparecem como células citoplasmaticamente densas contendo grandes glóbulos osmofílicos que, por mecanismos de transportecelular, são eventualmente depositados entre a parede celular e o plasmalema, presumivelmente associados à rizosecreção (BAERSON et al., 2008b). Tricomas de sorgo maduro possuem todo o material genético e a maquinaria bioquímica necessária para a produção desta benzoquinona bioativa (DAyAn et al., 2009a). O exsudado das raízes é sensível à temperatura do ambiente, sugerindo que o melhor funcionamento alelopático do sorgo seja entre $25^{\circ} \mathrm{C} \mathrm{e} 35^{\circ} \mathrm{C}$ (DAYAN, 2006). Além disso, foi demonstrado que a formação dos tricomas é inibida pelo excesso de água e que o etileno promove o desenvolvimento dos tricomas em tais condições (Hess et al., 1992; YANG et al., 2004). Principalmente por este motivo, o sorgo é um grão recomendado para atuar com seus efeitos alelopáticos em regiões com pouca disponibilidade de água.

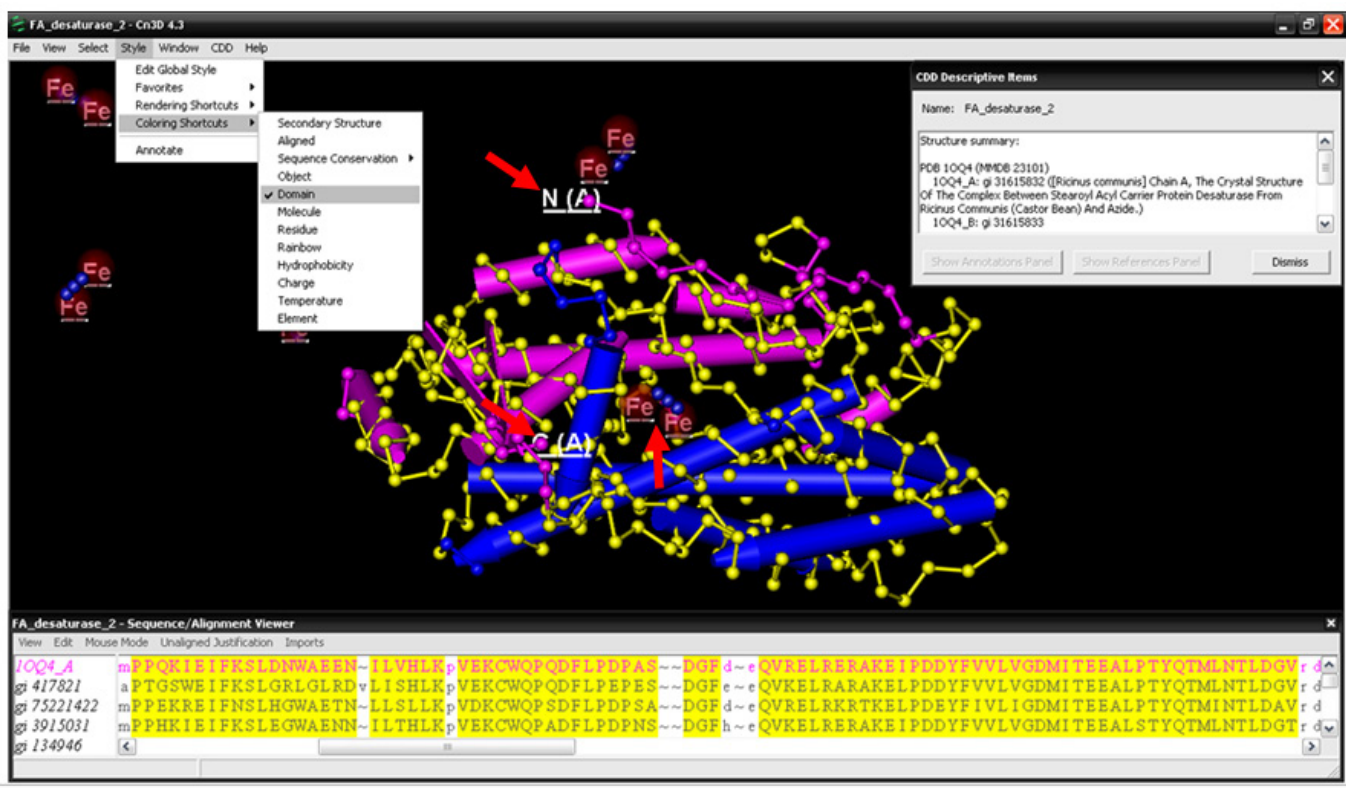

Fig. 2 - Desaturase putativa de Ricinus communis resolvida por difração de raios X exibindo seus dois domínios. Abaixo estão os segmentos dos aminoácidos conservados em relação às desaturases de sorgo marcados em amarelo, íons diférricos e as cadeias N-Terminal e Carboxi-Terminal indicadas por setas vermelhas.

Fonte: http:/ / www.ncbi.nlm.nih.gov/Structure/cdd/cddsrv.cgi?ascbin=8\&maxaln=10\&seltype=2\&uid=189569

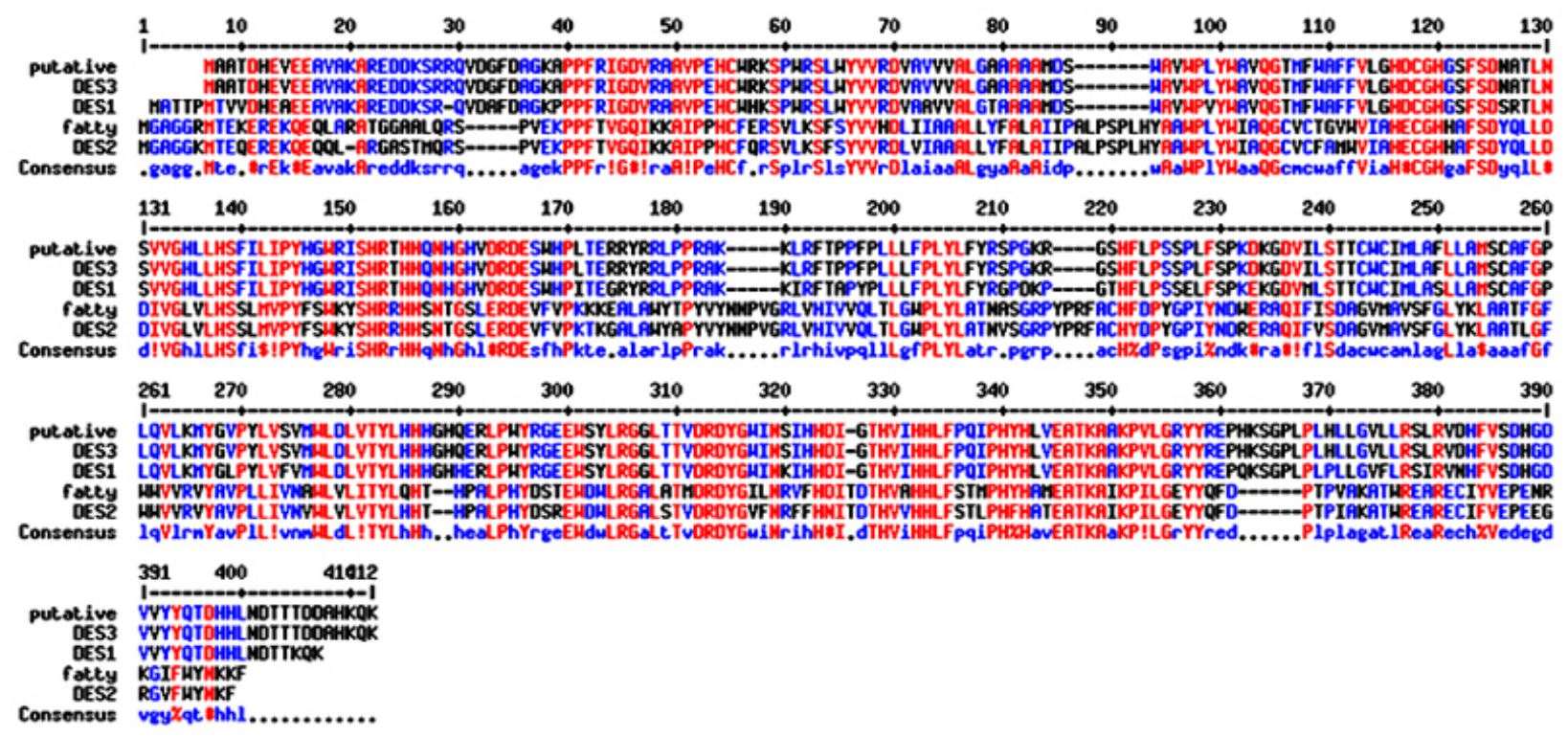

Fig. 3 - Cinco desaturases principais de Sorghum bicolor (DES1, DES2 e DES3) comparadas com as desaturases (Putative e Fatty) e alinhadas com o programa MultAlin (http://multalin.toulouse.inra.fr/multalin/multalin.html) é possível observar os gaps (traços), as regiões conservadas (vermelho) e os mismatches (azul). 
Estudos moleculares estão desvendando a rota metabólica do sorgoleone, e vários genes de desaturases envolvidas na sua rota de produção já foram identificados e caracterizados (PAN etal., 2007; BAERSON et al., 2008b; COOK et al., 2010). Desaturases também estão presentes em algumas outras cultivares como a Oryza sativa (arroz), Ricinus communis (mamona) e o Triticum aestivum (trigo), no entanto, a maior eficiência de sua produção é verificada nas raízes de sorgo. Estudos de isolamento e sequenciamento nucleotídico do gene que codifica este tipo de proteína em sorgo demonstraram uma variação na estrutura quando comparada com outras espécies. Essas variações podem ter implicações nas vias biossintéticas de formação do exsudado sorgoleone. Alterando suas taxas transcricionais e traducionais a produção da benzoquinona lipídica pelos tricomas pode sofrer aumento ou diminuição. Isto dependeria principalmente das interações e dos dobramentos ocorridos na estrutura tridimensional da proteína devido às modificações co- e pós-traducionais. Por ser uma molécula de difícil manipulação ela ainda não foi cristalografada de sorgo. Este fato dificulta a modelagem computacional com base apenas em sequências nucleotídicas e protéicas de outros organismos devido à falta de parâmetros comparativos eficientes nos bancos de dados de proteínas para a construção de modelos compatíveis. Contudo, existe uma boa perspectiva de que esse problema seja brevemente solucionado pelo fato de que outras desaturases tiveram suas estruturas resolvidas por cristalografia ou difração de raios X como é o caso desta putativa desaturase de ácidos graxos presente em R. communis (mamona) (Fig. 2).

Em verdade, existem cinco sequências principais de desaturases obtidas de amostras de Sorghum bicolor no banco de dados de sequências proteicas do NCBI. Quando essas moléculas são alinhadas as sequências de desaturases DES 1 (GenBank: ABN49519.1), DES 2 (GenBank: ABN49520.1) e DES 3 (GenBank: ABN49521.1) apresentam uma grande semelhanças entre si (PAN et al., 2007). Entre elas a DES2 possui mais mal pareamentos de aminoácidos quando comparada com a DES 1 e DES 3. Por outro lado, a DES 2 se assemelha muito mais a sequência de desaturase de ácidos graxos "fatty" (GenBank: ACA28704.1). Além dessas, há a putativa desaturase de ácidos graxos "putative" descrita por YANG et al. (2004) (GenBank: AAT72937.1). Todas essas sequências podem ser vistas na (Fig. 3).

Estudos anteriores e em curso sugerem que a via biossintética para este composto ocorre nas células dos tricomas envolvendo uma atividade de poliquetídeo sintase que utiliza uma unidade de ácido graxo atípica 16:3 acil-CoA como precursora de partida, resultando na formação de um pentadecatrienol resorcinol intermediário. Modificações subsequentes deste intermediário resorcinólico são provavelmente mediadas dependentemente de S-adenosilmetionina e O-metiltransferases e depois uma dihidroxilação pela $\mathrm{P} 450$ monoxigenase (DAYAN et al., 2003; DAYAN et al., 2010). Embora a sequência exata de reações não seja conhecida, análises realizadas por espectrometria e cromatografia de massa de extratos das raízes do sorgo identificaram um éter 3-metil derivado do pentadecatrienol que é o provável resorcinol intermediário, indicando que a dihidroxilação do anel resorcinólico é precedido por uma O-metilação na posição 3' com a atividade de uma nova 5-n-alkilresorcinol com atividade de O-metiltransferase (BAERSON et al., 2008b). Para uma visão da via bioquímica com maiores detalhes recomendamos a leitura de (СоOK et al., 2010) onde ele discorre sobre as mais recentes suposições sobre o metabolismo dessa substância.

DAYAN (2006) identificou que os níveis de sorgoleone foram muito reprimidos pela exposição à luz azul e ocorreu uma ligeira redução pela luz vermelha, isso em relação ao controle de mudas crescendo no escuro. A base fisiológica da repressão da produção de sorgoleone continua a ser estudada, mas esses dados podem demonstrar uma regulação da via biossintética pelos fitocromos ou uma mudança na alocação de carbono.

\section{Atividade biológica}

Um dos mais bem caracterizados mecanismos de indução da fitotoxicidade por aleloquímicos como o sorgoleone é a inibição da fotossíntese pela evolução do oxigênio através das interações com componentes do fotossistema II (PSII) (CZARNOTAet al., 2001; YANGet al., 2004). Além disso, ela também atua no transporte de elétrons mitocondrial, interferindo na atividade da H+-ATPase e ainda na captura de água do solo (Hejl; Koster, 2004; Dayan et al., 2009b).

A principal função dos componentes do PSII é servir como uma armação incorporada à membrana. Esta armação organiza os elementos que se ligam a uma rede por excitação de pigmentos e outros cofatores que aprisionam, transferem e utilizam a energia solar para dirigir reações hidrolíticas (WEIR et al., 2004).

O sorgoleone é amplamente conhecido como um inibidor do PSII muito bem documentado (NIMBaL et al., 1996b; RiMANDO et al., 1998; RiMANDO et al., 2003). Em estudos utilizando cloroplastos intactos e membranas tilacoides, o sorgoleone inibiu especificamente a cadeia transportadora de elétrons nos cloroplastos atuando de forma semelhante aos herbicidas do grupo das triazinas (Nimbal et al., 1996b). De fato, o sorgoleone atua de forma semelhante à inibição dos sítios de ligação do PSII a atrazina. Isto previne a redução de plastoquinona $B\left(Q_{B}\right)$ pela quebra da 
cadeia transportadora de elétrons entre a plastoquinona $A\left(Q_{A}\right)$ e a $Q_{B}$ (RIMANDO et al., 1998). Este tipo de inibição é característica dos DCMU (Diuron) e outros herbicidas tais como as s-triazinas, fenilureas, triazinonas, ureas, uracilas, biscarbamatos, e piridazinonas (Nimbal et al., 1996b).

Osorgoleone mais provavelmente atua comoum análogo de plastoquinona interferindo na ligação das plastoquinonas as proteínas do PSII. Muitos componentes semelhantes ao sorgoleone, tal como o 5-ethoxysorgoleone, são formados em menores quantidades nos exsudados de sorgo, mas de toda forma têm sido recentemente caracterizados com propriedades inibitórias do PSII semelhantes (WEIR et al., 2004). Em concentrações equivalentes aquelas dos herbicidas sintéticos, o sorgoleone demonstrou inibir a p-hidroxifenilpiruvato dioxigenase (HPPD) rompendo a biossíntese de carotenoides, resultando em branqueamento foliar (MEAzZA et al., 2002).

A inibição da fotossíntese pelo sorgoleone e seus semelhantes é uma inibição aleloquímica bem caracterizada, outras fitotoxinas têm mecanismo de atuação semelhante a este composto (WeIretal., 2004). Apesar de outros análogos ao sorgoleone também serem produzidos pelas raízes destas plantas, todos foram identificados atuando conjuntamente na inibição do fotossistema II (PSII) nos cloroplastos das plantas alvo (KAGAN et al., 2003; MARCHI et al., 2008).

\section{Importância agronômica}

Todos os anos cerca de $13 \%$ das culturas do mundo são perdidas devido a danos causados por plantas daninhas. O desenvolvimento da tecnologia decontrole das plantas daninhas, como transgênicos eherbicidas sintéticos, trouxe uma grande contribuição para a melhoria da produtividade das culturas ao longo dos anos. A perda na produção agrícola seria $500 \%$ maior sem o uso de herbicidas. Contudo, a resistência a herbicidas e a crescente aversão do público ao uso de herbicidas sintéticos na produção dealimentos favorecem o mercado a buscar controles mais eficazes e menos agressivos (Mizunoetal.,2010). Várias espécies de sorgo apresentam interferência alelopática ao desenvolvimento de plantas daninhas ou de outras culturas. É nesse atual contexto agronômico de consciência com a qualidade, sem esquecer da quantidade dos alimentos, que figura a principal importância da utilização do sorgoleone nesse tipo de controle biológico.

Na região Sul dos Estados Unidos os agricultores frequentementeutilizam híbridos desorgochamados "Sudex" (S. bicolor x S. sudanense) como cobertura verde ou de solo para prevenir a erosão e para reduzir a infestação de plantas daninhas. Sorgo granífero e sudanense são referidos como úteis em dificultar o desenvolvimento de plantas daninhas em pomares.
(TREZZI, 2002). EINHELLIG; SouZA (1992) observaram no Nordeste do Estado da Nebrasca, Estados Unidos, que a cultura do sorgo pode reduzir a infestação de plantas daninhas do próximo ano. A porcentagem de cobertura do solo com plantas daninhas era menor nas parcelas plantadas com sorgo no ano anterior do que naquelas com soja (Glycine max (L.) Merr.) ou milho (Zea mays L.). Os efeitos inibitórios do sorgo foram mais evidentes sobre as espécies de plantas daninhas de folhas largas que sobre as espécies de gramíneas (HALLAK et al., 1999; BARBOSA et al., 2001).

SiLva et al. (1986) verificaram que não havendo o controle das plantas daninhas nas quatro primeiras semanas após a emergência de algumas culturas de grãos comercialmente importantes, pode ocorrer uma redução na produção na ordem de $35 \%$. Em caso de não se empregar nenhum método de controle, esta redução pode chegar a aproximadamente $71 \%$ (EINHellig; SOUZA, 1992; Demuner et al., 2005). Neste sentido, o sorgo, que é uma espécie utilizada tanto para produção de grãos quanto como forrageira, torna-se importante por sua reconhecida alelopatia atuando contra as plantas daninhas favorecendo, assim, cultivos mais bioracionais seja quando ela é usada como monocultura, seja quando ela é rotacionada em sistemas consorciados (SILVA et al., 1986; SINGH et al., 2003).

Apesar de ser potencialmente importante para a agricultura, a atividade herbicida do sorgoleone é mais forte em plantas daninhas de sementes pequenas. Plantas daninhas com sementes grandes tendem a serem menos sensíveis ao sorgoleone. Essas plantas podem evitar o efeito de herbicidas por menor absorção e translocação ou, ainda, por possuírem uma degradação metabólica mais rápida dos aleloquímicos, ou, simplesmente, por terem raízes crescendo rapidamente além da zona da rizosfera do sorgo onde se acumula o sorgoleone (DAYAN, 2006, DAYAN et al., 2010).

\section{CONCLUSÕES}

As importantes propriedades herbicidas e alelopáticas do sorgoleonefazem do estudo eisolamento dos genes e substâncias responsáveis pela sua biossíntese um fato desejável tanto para a engenharia genética quanto para a agricultura mundial, bem como a sua manipulação no próprio sorgo e a sua introdução em outras espécies decultivares. Isto pode prover um melhor entendimento da função deste composto lipídico nas interações entre as plantas, além de melhorar o entendimento dos mecanismos de controle biológico natural causado por essa substância, seus análogos, resíduose adjuvantes. A excelente capacidade de supressão das plantas daninhas por esta benzoquinona lipídica com intensa atividade 
biológica, utilizando coberturas graminíferas de sorgo devido a sua fitotoxicidade, oferece interessantes possibilidades para abordagens biorracionais mais eficazes no controle das ervas daninhas e na qualidade dos grandes cultivares brasileiros.

\section{AGRADECIMENTOS}

À CAPES e ao CNPQ pela concessão de bolsas de pesquisa em nível de Desenvolvimento Tecnológico Industrial, Mestrado e de Doutorado. A todos os pesquisadores dessa e de outras instituições que de uma forma ou de outra contribuíram para a conclusão do trabalho.

\section{REFERÊNCIAS}

ARCHANGELO, E.R.; SILVA, J.B.; SILVA, A.A.; FERREIRA, L.R.; KARAM, D. Tolerância do sorgo forrageiro ao herbicida primestra SC. Revista Brasileira de Milho e Sorgo, v.1, n.2, p.59-66, 2002.

BAERSON, S.R.; SANCHEZ-MOREIRAS, A.; PEDROL-BONJOCH, N.; SCHULZ, M.; KAGAN, I.A.; AGARWAL, A.K.; REIGOSA, M.J.; DUKE, S.O. Detoxification and transcriptome response in Arabidopsis seedlings exposed to the allelochemical benzoxazolin-2(3H)-one. The Journal of Biological Chemistry, v.280, n.23, p.2186721881, 2005.

BAERSON, S.R.; RIMANDO, A.M.; PAN, Z. Probing allelochemical biosynthesis in sorghum root hairs. Plant Signaling \& Behavior, v.3, n.9, p.667-670, 2008a.

BAERSON, S.R.; DAYAN, F.E.; RIMANDO, A. M.; NANAYAKKARA, N.P.D.; LIU,C.J.; SCHRODER, J.; FISHBEIN, M.; PAN, Z.; KAGAN, I.A.; PRATT, L.H.M.; PRATT, M.C.; DUKE, S.O. A functional genomics investigation of allelochemical biosynthesis in Sorghum bicolor root hairs. The Journal of Biological Chemistry, v.283, n.6. p.3231-3247, 2008b.

BAIS, H.P.; PARK, S-W.; WEIR, T.L.; CALLAWAY, R.M.; VIVANCO, J.M. How plants communicate using the underground information superhighway. Trends in Plant Science, v.9, n.1, p.26-32, 2004.

BARBOSA, T.M.L.; FERREIRA, F.A.; SOUZA, I.F.; BARBOSA, L.C.A.; CASALI, V.W.D. Caracterização química e efeitos alelopáticos de exsudatos radiculares de plântulas de sorgo sobre Alface. Planta Daninha, v.16, n.2, p.153-162, 1998.

BARBOSA, L.C.A.; FERREIRA, M.L.; DEMUNER, A.J.; SILVA, A.A.; PEREIRA, R.C. Preparation and phytotoxicity of sorgoleone analogues. Quimica Nova, v.24, n.6, p.751-755, 2001.
BARBOSA, L.C.A.; PEREIRA, U.A.; MALTHA, C.R.A.; TEIXEIRA, R.R.; VALENTE, V.M.M.; FERREIRA, J.R.O.; COSTA-LOTUFO, L.V.; MORAES, M.O.; PESSOA, C. Synthesis and biological evaluation of 2,5-Bis(alkylamino)-1,4-benzoquinones. Molecules, v.15, p.5629-5643, 2010.

BELZ, R.G. Allelopathy in crop/weed interactions - an update. Pest Management Science, v.63, p.308-326, 2007.

BLAIR, A.C.; WESTON, L.A.; NISSEN, S.J.; BRUNK, G.R.; HUFBAUER, R A. The importance of analytical techniques in allelopathy studies with the reported allelochemical catechin as an example. Biol Invasions, v.11, p.325-332, 2009.

COMPANHIA NACIONAL DE ABASTECIMENTO (Brasil). Brasília, DF: CONAB, 2011. Disponível em: <www.conab.gov.br/conabweb/>. Acesso em: 28 jul. 2011.

COOK, D.; RIMANDO, A.M.; CLEMENTE, T.E.; SCHRODER, J.; DAYAN, F.E.; NANAYAKKARA, N.P.D.; PAN, Z.; NOONAN, B.P.; FISHBEIN, M.; ABE, I.; DUKE, S.O.; BAERSON, S.R. Alkylresorcinol synthases expressed in Sorghum bicolor root hairs play an essential role in the biosynthesis of the allelopathic benzoquinone sorgoleone. The Plant Cell, v.22, p.867-887, 2010.

CZARNOTA, M.A.; PAUL, R.N.; DAYAN, F.E.; NIMBAL, C.I.; WESTON, L.A. Mode of action, localization of production, chemical nature, and activity of sorgoleone: a potent PSII inhibitor in Sorghum spp. root exudates. Weed Technology. v.15, p.813-825, 2001.

DAYAN, F.E.; KAGAN, I.A.; RIMANDO, A.M. Elucidation of the biosynthetic pathway of the allelochemical sorgoleone using retrobiosynthetic NMR analysis. The Journal of Biological Chemistry, v.278, n.31, p.28607-28611, 2003.

DAYAN, F.E. Factors modulating the levels of the allelochemical sorgoleone in Sorghum bicolor. Planta, v.224, p.339-346, 2006.

DAYAN, F.E.; WATSON, S.B.; NANAYAKKARA, N.P.D. Biosynthesis of lipid resorcinols and benzoquinones in isolated secretory plant root hairs. Journal of Experimental Botany, v.58, n.12, p.6263-3272, 2007.

DAYAN, F.E.; CANTRELL, C.L.; DUKE, S.O. Natural products in crop protection. Bioorganic $\mathcal{E}$ Medicinal Chemistry, v.17, p.4022-4034, 2009a.

DAYAN, F.E.; HOWELL, J.L.; WEIDENHAMER, J.D. Dynamic root exudation of sorgoleone and its in planta mechanism of action. Journal of Experimental Botany, v.60, n.7, p.2107-2117, 2009b.

DAYAN, F.E.; RIMANDO, A.M.; PAN, Z.; BAERSON, S.R.; GIMSING, A.L.; DUKE, S.O. Sorgoleone. Phytochemistry, v.71, p.1032-1039, 2010. 
DEMUNER, A.J.; BARBOSA, L.C.A.; CHINELATTO, L.S.; SILVA, C.R.A.A. Sorção e persistência da sorgoleona em um latossolo vermelho-amarelo. Química Nova, v.28, n.3, p.451-455, 2005.

EINHELLIG, F.; SOUZA, I. Phytotoxicity of sorgoleone found in grain sorghum root exudates. Journal of Chemistry Ecology, v.18, n.1, p.1-11, 1992.

FUNNELL-HARRIS, D.L.; PEDERSEN, J.F.; MARX, D.B. Effect of sorghum seedlings, and previous crop, on soil fluorescent Pseudomonas spp. Plant and soil, v.311, n.1/2, p. 173-187, 2008.

GIMSING, A.L.; BAELUM, J.; DAYAN, F. E.; LOCKE, M. A.; SEJERØ, L. H.; JACOBSEN, C.S. Mineralization of the allelochemical sorgoleone in soil. Chemosphere, v.76, n.8, p.1041-1047, 2009.

GOLISZ, A.; SUGANO, M.; FUJII, Y. Microarray expression profiling of Arabidopsis thaliana L. in response to allelochemicals identified in buckwheat. Journal of Experimental Botany, v.59, n.11, p.3099-3109, 2008.

HALLAK, A.M.G.; DAVIDE, L. C.; SOUZA, I.F. Effects of sorghum (sorghum bicolor L.) root exudates on the cell cycle of the bean plant (Phaseolus vulgaris L.) root. Genetics and Molecular Biology, v.22, n.1, p.95-99, 1999.

HEJL, A.M.; KOSTER, K.L. The allelochemical sorgoleone inhibits root $\mathrm{H}+-\mathrm{ATPase}$ and water uptake. Journal of Chemical Ecology, v.30, n.11, p.2181-2191, 2004.

HESS, D.E.; EJETA, G.; BUTTLER, L.G. Selection of sorghum genotypes expressing a quantitative biosynthetic trait that confers resistance to Striga. Phytochemistry, v.31, n.2, p.493-497, 1992.

KAGAN, I.A.; RIMANDO, A.M.; DAYAN, F.E. Chromatographic separation and in vitro activity of sorgoleone congeners from the roots of Sorghum bicolor. Journal of Agricultural and Food Chemistry, v.51, n.26, p.7589-7595, 2003.

LAOPAIBOON, L.; NUANPENG, S.; SRINOPHAKUN, P.; KLANRIT, P.; LAOPAIBOON, P. Ethanol production from sweet sorghum juice using very high gravity technology: Effects of carbon and nitrogen supplementations. Bioresource Technology, v.100, n.18, p.4176-4182, 2009

MACÍAS, F.A.; MOLINILLO, J.M.G.; VARELA, R.M.; GALINDO, J.C.G. Allelopathy - a natural alternative for weed control. Pest Management Science, v.63, n.4, p.327348, 2007.

MARCHI, G.; MARCHI, E.C.S.; WANG, G.; MCGIFFEN, M. Effect of age of a sorghum-sudangrass hybrid on its allelopathic action. Planta Daninha, v.26, n.4, p.707-716, 2008.
MEAZZA G.; SCHEFFLER, B.E.; TELLEZ, M.R.; RIMANDO, A.M.; ROMAGNI, J.G.; DUKE, S.O.; NANAYAKKARA, D.; KHAN, I.A.; ABOURASHED, E.A.; DAYAN, F.E. The inhibitory activity of natural products on plant p-hydroxyphenylpyruvate dioxygenase. Phytochemistry, v.60, n.3, p.281-288, 2002.

MEDRAOUI, L.; ATER, M.; BENLHABIB, O.; MSIKINE, D.; FILALI-MALTOUF, A. Evaluation of genetic variability of sorghum (Sorghum bicolor L. Moench) in northwestern Morocco by ISSR and RAPD markers. Comptes Rendus. Biologies, v.330, n.11, p,789-797, 2007.

MIZUNO, C.S.; RIMANDO, A.M.; DUKE, S.O. Phytotoxic activity of quinone and resorcinolic lipid derivatives. Journal of Agricultural and Food Chemistry, v.58, p.4353-4355, 2010.

NIMBAL, C. I.; PEDERSEN, J. F.; YERKES, C. N.; WESTON, L. A.; WELLER, S. C. Phytotoxicity and distribution of sorgoleone in grain sorghum germplasm. Journal of Agricultural and Food Chemistry, v.44, p.1343-1347, 1996a.

NIMBAL, C.I.; YERKES, C.N.; WESTON, L.A.; WELLER, S.C. Herbicidal activity and site of action of the natural product sorgoleone. Pesticide Biochemistry and Physiology, v.54, n.11, p.73-83, 1996b.

PAN Z.; RIMANDO, A.M.; BAERSON, S.R.; FISHBEIN, M.; DUKE, S.O. Functional characterization of desaturases involved in the formation of the terminal double bond of an unusual 16:3 $\Delta 9,12,15$ fatty acid isolated from Sorghum bicolor root hairs. The Journal of Biological Chemistry, v.282, n.7, p.4326-4335, 2007.

RIMANDO, A.M.; DAYAN, F.E.; CZARNOTA, M.A.; WESTON, L.A.; DUKE, S.O. A new photosystem II electron transport inhibitor from Sorghum bicolor. Journal of Natural Products, v.61, n.7, p.927-930, 1998.

RIMANDO, A.M.; DAYAN, F.E.; STREIBIG, J.C. PSII Inhibitory Activity of resorcinolic lipids from Sorghum bicolor. Journal of Natural Products, v.66, n.1, p.42-45, 2003.

SANTOS, I.L.V.L; SILVA, P.G.; LIMA JÚNIOR, S.F.; SOUZA, P.R.E.; TABOSA, J.N.; MAIA, M.M.D. Utilização de RAPD na caracterização molecular de acessos de sorgo (Sorghum bicolor L. Moench) recomendados para o semi-árido de Pernambuco. Revista Brasileira de Ciências Agrárias, v.5, n.1, p.60-66, 2010.

SILVA, J.B.; PASSINI, T.; VIANNA, A.C. Controle de plantas daninhas na cultura do sorgo. Informe Agropecuário, v.12, n.144, p.43-45, 1986.

SINGH H.; BATISH, D.; KOHLI, R. Allelopathic interactions and allelochemicals: new possibilities for sustainable weed management. Critical Reviews in Plant Science, v.22, p.239-311, 2003 
TABOSA, J.N.; REIS, O.V.; BRITO, A.R.M.B.; MONTEIRO, M.C.D.; SIMPLÍCIO, J.B.; OLIVEIRA, J.A.C.; SILVA, F.G.; NETO, A.D.A.; DIAS, F.M.; LIRA, M.A.; FILHO, J.J.T.; NASCIMENTO, M.M.A.; LIMA, L.E.; CARVALHO, H.W.L.; OLIVEIRA, L.R. Comportamento de cultivares de sorgo forrageiro em diferentes ambientes agroecológicos dos estados de Pernambuco e Alagoas. Revista Brasielira de Milho e Sorgo. v.1, n.2, p.47-58, 2002.

TREZZI, M.M. Avaliação do potencial alelopático de genótipos de sorgo. 2002. 127f. Tese (Doutorado em Fitotecnia) - Universidade Federal do Rio Grande do Sul, Porto Alegre, 2002.

UDDIN, M.R.; PARK, K.W.; KIM, Y.K.; PARK, S.U.; PYON, J.Y. Enhancing sorgoleone levels in grain sorghum root exudates. Journal of Chemical Ecology, v.36, n.8, p.914-922, 2010.

WEIR, T.L.; PARK, S.W.; VIVANCO, J.M.. Biochemical and physiological mechanisms mediated by allelo- chemicals. Current Opinion in Plant Biology, v.7, n.4, p.472-479, 2004.

WU, H.; PRATLEY, H.; LEMERLE, D.Y.; HAIG, T. Crop cultivars with allelopathic capability. Weed Research, v.39, n.3, p.171-180, 1999.

WU, H.; WALKER, S.R.; OSTEN, V.A.; ROBINSON, G. Competition of sorghum cultivars and densities with Japanese millet (Echinochloa esculenta). Weed Biology Management, v.10, n.3, p.185-193, 2010.

YANG, X.; SCHEFFLER, B.E.; LESLIE, A. Weston SOR1, a gene associated with bioherbicide production in sorghum root hairs. Jornal of Experimental Botany, v.55, n.406 p.2251-2259, 2004.

Recebido em 21/6/10

Aceito em 17/11/11 